\title{
Aflatoxin B1 Residues in Eggs and Flesh of Laying Hens Fed Aflatoxin B1 Contaminated Diet
}

\author{
Saqer Mohammad Herzallah
}

Department of Nutrition and Food Science, Faculty of Agriculture, Mu'tah University, Karak, Jordan

Received 2013-04-30, Revised 2013-07-06; Accepted 2013-07-08

\begin{abstract}
Aflatoxin B1(AFB1) and total Aflatoxins (AFT) contaminated feed effect on aflatoxins residue level in eggs, muscles (breast, leg), organs (liver, kidney, gizzard) and excreted aflatoxins in chicken litter of layer hens were monitored. Laying hens were on four levels of aflatoxins for 6 weeks and monitored weekly for the change in both AFB1 and AFT levels. Pronouncedly, the AFB1 and AFT were detected in eggs, muscles (legs, breast), organs (liver, kidney and gizzard) and litter in noticeable amounts. Total Aflatoxin (AFT) level was lowest in chicken breast $(0.63 \mathrm{ppb})$ and highest in liver $(2.12 \mathrm{ppb})$ and gizzard (1.22 ppb) of chicken fed diet with $965.12 \mathrm{ppb}$. Whereas, AFB1 residue was $0.66 \mathrm{ppb}$ in eggs, $1.59 \mathrm{ppb}$ in liver tissues of hens given feed contaminated with $894.12 \mathrm{ppb}$. Residue level of AFB1 was high in liver and kidney of all treatments. The chicken breast tissues were lowest in AFB1 and AFT of values 0.72 and 0.63 , respectively. Eggs production was significantly $(p<0.05)$ affected with AFB1 contaminated feed and egg production was decreased by more than $30 \%$.
\end{abstract}

Keywords: Aflatoxins, AFT, AFB1, Dose/Residue, Layers

\section{INTRODUCTION}

Mycotoxins are group of toxic compounds detected in 1960s (Asao et al., 1965) known as bisfuranocoumarines compounds found in grains contaminated with Aspergillus flavus and Aspergillus parasiticus, with aflatoxin B1 (AFB1) as the most potent toxins of teratogenic, mutagenic and carcinogenic effect (Mishra and Das, 2003; IARC, 2002; Williams et al., 2009; Manning et al., 2005; Bintvihok et al., 2003; Khan et al., 2010; Arana et al., 2011). Animals are considered the most group exposed to high concentration of aflatoxins through feedstuffs that develop several health problems which lead to large economical losses. These losses are pronouncing in meat and eggs in terms of quality and quantity as a result of contamination with aflatoxins residues (Bintvihok et al., 2002; Farombi, 2006; Hall and Wild, 2003). Feeds of cereal grain origin demonstrate the most susceptible commodities along with nuts for contamination with AFG1, AFG2 and AFB2 in addition to AFB1 as the main toxins contaminants. Grain contamination with aflatoxins recognized as a threat to human and animals through consumption of contaminated foods and feeds and considered by FDA as an avoidable contaminant (Kim et al., 2000). Food and Agricultral Organization (FAO) estimated the contamination with the mycotoxins by $25 \%$ of the produced world's crops (Fink-Gremmels, 1999). Therefore, the food chain of animal origin are considered the most vulnerable and the most affected by the presence of aflatoxins which varies with age and species of the animals (Williams et al., 2009; Manning et al., 2005). The level of AFB1 adopted in most of the world countries is $5 \mathrm{ppb}$ regulatory as a level of human contamination risk (Yosef et al., 2003). Marine animals also could be exposed to AFB1 contamination through feed chain and thus exerts threat to human when the concentration were higher than the permitted levels (Farabi et al., 2006). Epidemiological research proves the effect of AFB1 as a causative agent for liver cancer and human health hazards threats associated with food chain contamination with AFB and their metabolites 
such as M1 in milk are of food safety authorities to avoid entrance of the contaminated commodities into suitability for consumption and to avoid AFB1 contaminated food that pose threat and hazards to human through food consumption. The objective of this study was to determine the residual effect of AFB1 and Total aflatoxins in poultry flesh and eggs.

\section{MATERIALS AND METHODS}

Sixty of 23-week-old layers chicken (Hubbard) were used and fed ad libitum with a standard layer diet for 2-week-period, during which daily egg production were recorded. The birds were divided into 4 groups each of 15 birds fed with standard layer and broiler diet (Table 1) obtained from a commercial feed company was used as a basal feed and with artificially challenged with $0,190.02,395.31$ and 894.12 ppb AFT B1. The eggs from all groups were collected, recorded daily and the AFB1 residues were determined weekly as well. The residual of the AFB1 in flesh of the layer chickens used in the experiment were determined at the end of 5 week of production.

\subsection{Chemical and Reagent}

Anhydrous sodium sulphate $\geq 99 \%$, diatomaceous earth, $\mathrm{NaCl}(99 \%)$, aflatoxins Kit standard of AFB1, AFB2, AFG1 and AFG2 of 98\% purity, Methanol of 99.5\% and Hexane were purchased from Sigma-Aldrich (St Louis, MO, USA). Acetone (BDH chemicals, Ltd, Liverpool, UK) SPE-CN was purchased from Varian (Palo Alto, California, USA) and aflatoxin Immunoaffinity Columns (IAC) purchased from rbiopharm (R-Biopharm, Darmstadt, Germany).

\subsection{Test Protocol}

Aflatoxins of a finally ground feed samples (2-g) was extracted by mixing with 10-mL of 70:30 (methanol: distilled water) for $30 \mathrm{~min}$ at room temperature (20$25^{\circ} \mathrm{C}$ ) using a shaker at $2000 \mathrm{rpm}$ ( IKA, Mount Holly, NJ, USA). The mixture was filtered through Whtman no. 1 filter paper ( Whatman, Hamburg, Germany) and a 100- $\mu \mathrm{L}$ of the eluate diluted 1: 6 with sample dilution buffer (Phosphate buffer solution, $\mathrm{pH}$ 7.2). The aflatoxin was determined using r-biopharm kit. Poultry muscles, eggs and organs (liver, kidney, gizzard) were extracted by a method used by Herzallah (2009), in brief, 50-g of poultry muscles, eggs and organ representative homogenized samples were blended at high speed blender (balck and Dickers, UK) with 100 $\mathrm{mL}$ of water and acetone $(1: 1)$ mixture for $10 \mathrm{~min}$, then diatomaceous earth was added to the mixture, stirred gently for $5 \mathrm{~min}$, filtered through fast filtering paper and $10-\mathrm{mL}$ of the filtrate was mixed with $5 \% \mathrm{NaCl}$ and Hexane (1:1). The mixture was shaken at $1200 \mathrm{rpm}$ for 20 min using a mechanical shaker (IKA, Hamburg, Germany), the hexane layer was removed out of the solution with care and discarded. The AFB1 was extracted with chloroform $(3 \times 50 \mathrm{~mL})$; the chloroform layer collected, dried over anhydrous sodium sulphate and evaporated using rotary evaporator. The residues were redissolved in $1 \mathrm{~mL}$ chloroform and cleaned over SPE-CN. The eluted aflatoxins were evaporated to dryness under a stream of $\mathrm{N}_{2}$, redissolved in methanol and analyzed by HPLC.

\subsection{HPLC Determination}

HPLC (Waters Co., MA, USA) equipped with 1525 binary HPLC pump, column oven $5 \mathrm{CH}$ model and fluorescence detector (Model FL 2475) at wavelength 365 and $425 \mathrm{~nm}$ for excitation and emission, respectively, was used in AFB1 analysis.

Table 1. Feed composition of experimental layer diet used in the study ${ }^{1,2,3}$

\begin{tabular}{|c|c|}
\hline Ingredients & $\%$ \\
\hline Corn & 60.50 \\
\hline Soybean meal & 21.50 \\
\hline Vegetable oil & 3.00 \\
\hline Limestone & 8.66 \\
\hline DCP & 0.49 \\
\hline Salt & 0.20 \\
\hline DL-Methionine & 0.11 \\
\hline L-Lysine & 0.94 \\
\hline Coccidiostat & 0.00 \\
\hline Vitamin premix & 0.25 \\
\hline Mineral premix & 0.10 \\
\hline Choline chloride & 0.10 \\
\hline Antixidant & 0.10 \\
\hline Antifungal & 0.10 \\
\hline $\begin{array}{l}\text { Analysis: Metabolizable energy } \\
\text { (kcal/kg of dry matter) }\end{array}$ & 2907.48 \\
\hline $\mathrm{CP}(\%)$ & 18.00 \\
\hline NPP (\%) & 0.43 \\
\hline $\mathrm{Ca}(\%)$ & 3.80 \\
\hline $\mathrm{Na}(\%)$ & 0.18 \\
\hline \multicolumn{2}{|c|}{$\begin{array}{l}{ }^{\mathrm{T}} \text { Each } \mathrm{kg} \text { of vitamin premix contains } 2.4 \times 10^{6} \mathrm{IU} \text { vitamin } \mathrm{A} \text {; } \\
3.2 \times 10^{5} \text { vitamin } \mathrm{D} 3 ; 5.6 \times 10^{3} \mathrm{mg} \text { vitamin } \mathrm{E}, 640 \mathrm{mg} \text { vitamin } \\
\mathrm{K} 3 ; 500 \mathrm{mg} \text { vitamin } \mathrm{B} 1 ; 1120 \mathrm{mg} \text { vitamin } \mathrm{B} 2,3200 \mathrm{mg} \text { niacin; } \\
1600 \mathrm{mg} \mathrm{Ca}-\mathrm{D}-\text { pantothenate; } 800 \text { vitamin } \mathrm{C}, 2.4 \mathrm{mg} \text { vitamin } \\
\mathrm{B} 12,160 \mathrm{mg} \text { folic acid; } 7.2 \mathrm{mg} \text { D-biotin; } 8000 \mathrm{mg} \text { vitamin } \mathrm{C} \text {; } \\
20000 \mathrm{mg} \text { choline chloride; }{ }^{2} \text { Each } \mathrm{kg} \text { of mineral premix } \\
\text { contains } 8 \times 10^{4} \mathrm{mg} \text { manganese; } 6 \times 10^{4} \mathrm{mg} \text { zinc; } 200 \mathrm{mg} \text { cobalt; } \\
100 \mathrm{mg} \text { iodine; } 150 \mathrm{mg} \text { selenium; }{ }^{3} \mathrm{DCP} \text {, dicalcium phosphate; } \\
\mathrm{CP} \text {, crude protein; } \mathrm{NPP} \text {, non phytate phosphorous }\end{array}$} \\
\hline
\end{tabular}


Thermo LC-Si column $(250 \times 4.6 \mathrm{~mm}$ id $)$ kept in column oven at $40^{\circ} \mathrm{C}$ and the flow rate of isocratic mobile phase composed of toluene, ethyl acetate, formic acid and methanol (90:5:2.5:2.5, v/v/v/v) was set at $2.0 \mathrm{~mL} \mathrm{~min}^{-1}$.

\subsection{Recovery of Aflatoxins}

The standard curve for AFB1 was linear with correlation coefficient of 0.999 and the Mean coefficient of Variation was $1.32 \%$ for AFB1 with a Minimum Detection Limit (MDL) of $0.05 \mathrm{ppb}$.

\subsection{Statistical Analysis}

Results were analyzed for statistical significance $(p<0.05)$ by analysis of variance using GLM and Duncan's Multiple Range of SAS version 9.0 software (SAS, 2007) to reduce the data. The significance was evaluated through mean values that showed significant differences in the Least Significant Difference (LSD) procedure if $\mathrm{p}<0.05$.

\section{RESULTS}

Eggs produced by layer hens fed AFB1 contaminated feed with $894.12 \mathrm{ppb}$ found to contain higher level of AFB1 (0.66 ppb) than eggs and/or flesh from hens fed a diet of 190.02 ppb AFB1 concentration that cause a residual effect of $0.33 \mathrm{ppb}$ as shown in Table 2. The muscle and organs of layer hens after 7 weeks of production and fed diet contaminated with AFB1 and Total AF were found to contain higher levels of AFT and AFB1 with an increase in the levels feed aflatoxin concentration, of feed contaminated with 894.12 or $965.61 \mathrm{ppb}$ and 190.02 or $192.61 \mathrm{ppb}$ for AFB1 and AFT, respectively (Table 2 and 3 ).

Liver of layer hens was higher in residue level of AFT $(2.12$ and $<0.51)$ with significant $(\mathrm{p}<0.05)$ difference. The results found in this study for kidney, gizzard, leg (drumstick and thigh), liver, feed and litter are presented in Table 2 and 3. The egg production by layer hens was decrease as the level of AFB1 or AFT in contaminated feed increased by $\geq 30 \%$ as shown in the data presented in Table 4 .
Table 2. Aflatoxin B1 content of Eggs from hens fed aflatoxin contaminated feeds $\mathrm{s}^{1,2,3}$

\begin{tabular}{|c|c|c|c|}
\hline \multirow{3}{*}{$\begin{array}{l}\text { Sample } \\
\text { Description }\end{array}$} & \multicolumn{3}{|c|}{ Treatment } \\
\hline & $\mathrm{T} 1$ & $\mathrm{~T} 2$ & $\mathrm{~T} 3$ \\
\hline & \multicolumn{3}{|c|}{$\mathrm{B} 1$ (ppb) } \\
\hline Feed & $894.12^{\mathrm{a}} \pm 5.12$ & $395.31^{\mathrm{a}} \pm 3.05$ & $190.02^{\mathrm{a}} \pm 3.16$ \\
\hline Eggs & $0.66^{\mathrm{d}} \pm 0.11$ & $0.43^{\mathrm{c}} \pm 0.21$ & $0.33^{\mathrm{d}} \pm 0.12$ \\
\hline Breast & $0.72^{\mathrm{d}} \pm 0.19$ & $0.52^{\mathrm{c}} \pm 0.17$ & $0.33^{\mathrm{d}} \pm 0.08$ \\
\hline Liver & $1.59^{\mathrm{c}} \pm 0.14$ & $0.86^{\mathrm{c}} \pm 0.13$ & $0.46^{\mathrm{cd}} \pm 0.07$ \\
\hline Kidney & $0.88^{\mathrm{d}} \pm 0.13$ & $0.59^{c} \pm 0.12$ & $0.44^{\mathrm{cd}} \pm 0.11$ \\
\hline Legs + Thigh & $0.78^{\mathrm{d}} \pm 0.12$ & $0.45^{\mathrm{c}} \pm 0.11$ & $0.30^{\mathrm{d}} \pm 0.12$ \\
\hline Gizzard & $1.22^{\mathrm{c}} \pm 0.16$ & $0.84^{\mathrm{c}} \pm 0.12$ & $0.76^{\mathrm{c}} \pm 0.12$ \\
\hline Litter & $26.06^{\mathrm{b}} \pm 0.17$ & $16.30^{\mathrm{b}} \pm 2.01$ & $6.50^{\mathrm{b}} \pm 1.04$ \\
\hline
\end{tabular}

Table 3. Residual effect of mycotoxin-contaminated feed on eggs and poultry flesh total aflatoxins (AFT)

\begin{tabular}{|c|c|c|c|}
\hline \multirow[b]{3}{*}{ Sample } & \multicolumn{3}{|c|}{ Treatment $^{1,2}$} \\
\hline & $\mathrm{T} 1$ & $\mathrm{~T} 2$ & $\mathrm{~T} 3$ \\
\hline & \multicolumn{3}{|c|}{ AFT (ppb) } \\
\hline Feed & $965.12^{\mathrm{a}} \pm 3.11$ & $467.27^{\mathrm{a}} \pm 4.01$ & $192.61^{\mathrm{a}} \pm 3.14$ \\
\hline Eggs & $1.54^{\mathrm{bc}} \pm 0.25$ & $0.71^{\mathrm{b}} \pm 0.29$ & $0.42^{\mathrm{b}} \pm 0.21$ \\
\hline Breast & $0.63^{\mathrm{d}} \pm 0.09$ & $<0.05^{4}$ & $<0.05$ \\
\hline Liver & $2.12^{\mathrm{b}} \pm 0.21$ & $1.02^{\mathrm{b}} \pm 0.12$ & $0.51^{b} \pm 0.16$ \\
\hline Kidney & $1.41^{\mathrm{c}} \pm 0.19$ & $0.61^{\mathrm{b}} \pm 0.10$ & $0.47^{\mathrm{b}} \pm 0.09$ \\
\hline $\begin{array}{l}\text { Legs (drumstick } \\
\text { and thigh) }\end{array}$ & $1.01^{\mathrm{cd}} \pm 0.11$ & $0.41^{\mathrm{b}} \pm 0.02$ & $<0.05$ \\
\hline Gizzard & $1.20^{\mathrm{cd}} \pm 0.11$ & $<0.05$ & $<0.05$ \\
\hline
\end{tabular}

${ }^{1}$ Values are mean of three readings $\pm \mathrm{SD} ;{ }^{2}$ Values of different superscript letter within column are significantly differ at $\mathrm{p}<0.05 ;{ }^{3}$ Total aflatoxins represent the sum values of $\mathrm{B} 1, \mathrm{~B} 2, \mathrm{G} 1$ and $\mathrm{G} 2 ;{ }^{4}$ Control samples contain $<0.05 \mathrm{ppb}$

Table 4. Eggs production of layer hens challenged with aflatoxin B1 in their ration ${ }^{1,2}$

\begin{tabular}{lll}
\hline & \multicolumn{2}{c}{ Eggs production (\%) } \\
Treatment & Group 1 & Group 2 \\
\hline Control & $90.0^{\mathrm{a}} \pm 2.10$ & $95.8^{\mathrm{a}} \pm 2.10$ \\
Treatment 1 & $50.0^{\mathrm{c}} \pm 1.80$ & $65.0^{\mathrm{c}} \pm 1.60$ \\
Treatment 2 & $70.0^{\mathrm{b}} \pm 2.00$ & $70.5^{\mathrm{b}} \pm 1.80$ \\
Treatment 3 & $70.0^{\mathrm{b}} \pm 2.30$ & $70.7^{\mathrm{b}} \pm 1.60$ \\
\hline
\end{tabular}

${ }^{1}$ Values are mean of three readings $\pm \mathrm{SD} ;{ }^{2}$ Values of different superscript letter within column are significantly differ at $\mathrm{p}<0.05$ 


\section{DISCUSSION}

The production of eggs largely affected by the concentration of AFB1 in the diet as its concentration increase the residue level increased. The residue level of 1.54 and $0.66 \mathrm{ppb}$ in eggs produced by layer hens fed AFT and AFB1, respectively, while, 0.71 and $0.42 \mathrm{ppb}$ AFT in eggs of hens fed diet of 467.27 and $192.61 \mathrm{ppb}$, respectively (Table 2 and 3). The increase in residue level of AFT (compared to control group) was less than the increase in residue level made by $965.12 \mathrm{ppb}$ AFT contaminated feed with no significant $(p>0.05)$ difference. The results of the residual effect of AFT on the residue levels in eggs was in agreement with Hussain et al. (2010) who found direct relationship between AFB1 in the diet and the residue level in liver, muscle and eggs. Also, the present results were in compliance with other of detectable residue in meat and eggs from chicken fed contaminated diet reported by previous reports (Hussain et al., 2010). The residual effect of feeds on the residue level in eggs for both AFB1 and AFT were obvious (Table 2 and 3) and the AFB1 was increased by $127 \%$, whereas, AFT increased by $294 \%$ for treatment 1 and 13 and $7 \%$ for treatment 3 (T3). The level of the residue was dose dependent and varies between treatments with significant $(\mathrm{p}<0.05)$ difference between treatment1 (T1) and treatments 2 and 3 (T1 and T3).

Egg production of laying hens fed a diet contaminated with different levels of AFB1 (894.12, $395.31,190.02,0)$ were found to be significantly $(\mathrm{p}<0.05)$ affected (Table 4). The reduction in egg production was $\geq 35 \%$ for treatment 1 and $\geq 30 \%$ for treatments 2 and 3 . These results were in agreement with data reported by Hamilton and Garlich (1971) that hens receiving 1.25 to $20 \mathrm{ppm}$ AFB1 in their diet decrease the egg production by 3 wk. However, AFB1 contaminated feed were found to be dose dependent in decreasing the egg production (Table 4). Also in agreement with reports by Denli et al. (2009) who found that AFB1 of $1 \mathrm{mg} \mathrm{kg}^{-1}$ affect strongly the performance of Chicken and Iqbal et al. (1983) who also found that diets with AFB1 levels of $600 \mathrm{ppb}$ affact egg characteristics and production by laying hens. Furthermore, the results of low egg production of layer hens could be attributed to the changes that AFB1 and AFT affect liver metabolism function that considered as a targeted organs by AFB1 (Osweiler et al., 2010; Zaghini et al., 2005; Bailey et al., 2006; Pasha et al., 2007; Miazzo et al., 2005). AFB1 also, cause drop in feed intake, decreased digestibility and liver lesions that hitherto lead to drop in egg production (Van Rensburg et al., 2006; Kermanshahi et al., 2007; AlShawabkeh et al., 2009; Shen et al., 2009; Kang and Lang, 2009).

Muscles of layer hens were tested for AFB1 and AFT residue level after 7 weeks production and found to follow same increasing approach of aflatoxin dose in feed of the given diet. The liver showed a significant $(p<0.05)$ rise in AFT against the residue level found in breast, kidney, gizzard and leg (drumstick and thigh) of the same treatment (Table 3). Leg (drumstick and thigh) had lower residue level of AFT this could be explained by the removal of part of the skin that contains the subcutaneous fat and hereafter aflatoxin level reduction. On the other hand, muscles or organs of challenged chicken such as liver, gizzard, legs (drumstick and thigh) and kidney, showed maximum value of AFT. A 2.12, 1.02 and $0.51 \mathrm{ppb}$ found in liver tissues of treatments 1 , 2 and 3 , respectively.

AFB1 residue in chicken muscles (Table 2) was similar in response of Dose/Residue (D/R) inclination level in eggs and poultry muscle. For example, the residue levels in layer hens liver was $1.59 \mathrm{ppb}$ with insignificant $(\mathrm{p}>0.05)$ difference amomg treatments 1,2 and 3. It was noticed that aflatoxin AFB1 amount in the diet determine the level of AFB1 residue level in poultry meat. The results were in agreement with the results found by Hussain et al. (2010) who found that the increase in the level of AFB1 in the diet increase the residue level in muscles of layer chickens and also in accordance with results reported by Zaghini et al. (2005) who found the increase in liver AFB1 and AFM1 with dose increase of AFB1 in feeds provided to broiler and laying hens. Metabolite disturbances and the withdrawal of aflatoxin in hens litter increases with egg production time after wk 7. The results were in agreement with the results found by Zaghini et al. (2005) who found that the use of mannanoligosaccharides increase adsorption of AFB1 to the polysaccharides and decrease the level in poultry muscles. AFB1 and AFT residue levels in eggs, muscles and organs of the layer hen and egg production were found to be dose dependent affected with the increase in the residue levels in eggs, animal flesh and egg production. The results found in the present study were in agreement with data reported by Denli et al. (2009) who found that AFB1 of $1 \mathrm{mg} / \mathrm{kg}$ affect strongly the performance of chicken and Iqbal et al. (1983) who found also that diets with AFB1 levels of $600 \mathrm{ppb}$ reduce egg characteristics and production by laying hens. 


\section{CONCLUSION}

Reduction in egg production and egg quality were resulted from using AFB1 contaminated chicken diet in feeding laying hens. AFB1 residue in laying hens' tissues and organs of liver, kidney, breast, legs, gizzard increased with increasing feed AFB1 concentration. AFB1 and AFT could contaminate the food produced from laying hens or eggs raised on AF contaminated feed. Additionally, litter generated from chicken fed artificially contaminated AFB1 had high AF residues and the level increased with increasing AFB1 contamination diet.

\section{ACKNOWLEDGMENT}

This study was supported by the grant from the Deanship of Academic Research at The University of Jordan.

\section{REFERENCES}

Al-Shawabkeh, K., S. Herzallah, A. Al-Fataftah and H. Zakaria, 2009. Effect of Aflatoxin B1 contaminated feed on broiler chickens performance and meat content of conjugated linoleic acid. Jordan J. Agric. Sci., 5: 314-323.

Arana, S., M.L.Z. Dagli, M. Sabino, Y.A. Tabata and M.G. Rigolino et al., 2011. Evaluation of the efficacy of hydrated sodium aluminosilicate in the prevention of aflatoxin-induced hepatic cancer in rainbow trout. Pesq. Vet. Bras., 31: 751-755. DOI: 10.1590/S0100-736X2011000900005

Asao, T., G.M. Buchi, M.A. Kader, G.B. Chang and E.L. Wich et al., 1965. The structure of aflatoxin B and G. J. Am. Chem. Soc., 87: 882-886. DOI: 10.1021/ja01082a031

Bailey, C.A., G.W. Latimer, A.C. Barr, W.L. Wigle and A.U. Haq et al., 2006. Efficacy of montmorillonite clay (NovaSil PLUS) for protecting full-term broilers from aflatoxicosis. J. Appl. Poult. Res., 15: 198-206.

Bintvihok, A., A. Ponpornpisit, J. Tangtrongpiros, W. Panichkriangkrail and R. Rattanapanee et al., 2003. Aflatoxin contamination in shrimp feed and effects of aflatoxin addition to feed on shrimp production. J. Food Prot., 66: 882-885. PMID: 12747701

Bintvihok, A., S. Thiengnin, K. Doi and S. Kumagai, 2002. Residues of aflatoxins in the liver, muscle and eggs of domestic fowls. J. Vet. Med. Sci., 64: 10371039. DOI: $10.1292 /$ jvms. 64.1037
Denli, M., J.C. Blandon, M.E. Guynot, S. Salado and J.F. Perez, 2009. Effects of dietary AflaDetox on performance, serum biochemistry, histopathological changes and aflatoxin. residues in broilers exposed to aflatoxin B1. Poultry Sci., 88: 1444-1451 DOI: 10.3382/ps.2008-00341

Farabi, S.M., M. Yousefian and A. Hajimoradloo, 2006. Aflatoxicosis in juvenile Huso huso fed a contaminated diet. J. Appl. Ichthy., 22: 234-237. DOI: $10.1111 /$ j.1439-0426.2007.00958.x

Farombi, E.O., 2006. Aflatoxin contamination of foods in developing countries: Implications for hepatocellular carcinoma and chemopreventive strategies. Afr. J. Biotech., 5: 1-14.

Fink-Gremmels, J., 1999. Mycotoxins: Their implications for human and animal health. Vet. Q., 21: 115-120. DOI: 10.1080/01652176.1999.9695005

Hall, A.J. and C.P. Wild, 2003. Liver cancer in low and middle income countries. Brit. Med. J., 326: 994995. DOI: 10.1136/bmj.326.7397.994

Herzallah, S.M,. 2009. Determination of aflatoxins in eggs, milk, meat and meat products using HPLC fluorescent and UV detectors. Food Chemistry 114: 1141-1146

Hussain, Z., M.K. Zargham, A. Khan, I. Javed and M.K. Saleem et al., 2010. Residues of aflatoxin B1 in broiler meat: Effect of age and dietary aflatoxin B1 levels. Food Chem. Toxicol., 48: 33040-3307. DOI: 10.1016/j.fct.2010.08.016

IARC, 2002. International Agency for Research on Cancer. Aflatoxins. IARC Monograph on the Evaluation of Carcinogenic Risks to Humans, 82, 171, IARC, World Health Organization, Lyon, France.

Iqbal, Q.K., P.V. Rao and S.J. Reddy, 1983. Doseresponse relationship of experimentally induced aflatoxicosis in commercial layers. Ind. J. Anim. Sci., 53: 1277-1280.

Kang, E.K. and K.A. Lang, 2009. Aflatoxin B1 and M1 contamination of animal feeds and milk from urban centers in Kenya. Afr. Health Sci., 9: 218-226. PMID: 21503172

Kermanshahi, H., M.R. Akbari, M. Maleki and M. Behgar, 2007. Effect of prolonged low level inclusion of aflatoxin B1 into diet on performance, nutrient digestibility, histopathology and blood enzymes of broiler chickens. J. Anim. Vet. Adv., 6: 686-692.

Khan, W.A., M.Z. Khan, A. Khan and I. Hussain, 2010. Pathological effects of aflatoxin and their amelioration by vitamin $\mathrm{E}$ in White Leghorn layers. Pakistan Vet. J., 30: 155-162. 
Kim, E.K., D.H. Shon, D. Ryu, J.W. Park and H.J. Hwang et al., 2000. Occurrence of aflatoxin M1 in Korean dairy products determined by ELISA and HPLC. Food Addit Contam., 7: 59-64. DOI: $10.1080 / 026520300283595$

Manning, B.B., H.L. Menghe and E.H. Robinson, 2005. Aflatoxins from moldy corn cause no reductions in channel catfish Ictalurus punctutus performance. J. World Aquaculture Soci., 36: 59-67. DOI: 10.1111/j.1749-7345.2005.tb00131.x

Miazzo, R., M.F. Peralta, C. Magnoli, M. Salvano and S. Ferrero et al., 2005. Efficacy of sodium bentonite as a detoxifier of broiler feed contaminated with aflatoxin and fumonisin. Poultry Sci., 84: 1-8. PMID: 15685935

Mishra, H.N. and C. Das, 2003. A review on biological control and metabolism of aflatoxin. Critical Rev. Food Sci. Nutr., 43: 245-264. DOI: 10.1080/10408690390826518

Osweiler, G.D., S. Jagannatha, D.W. Trampel, P.M. Imerman and S.M. Ensley et al., 2010. Evaluation of XPC and prototypes on aflatoxin-challenged broilers. Poultry Sci., 89: 1887-1893. DOI: 10.3382/ps.2010-00773

Pasha, T.N., M.U. Farooq, F.M. khattak, M.A. Jabber and A.D. Khan, 2007. Effectiveness of sodium bentonite and two commercial products as aflatoxin absorbents in diets for broiler chickens. Anim. Feed Sci. Techn., 132: 103-110. DOI: 10.1016/j.anifeedsci.2006.03.014
SAS, 2007. SAS usersn Guide version 9. SAS Institute, Inc., Cary, N.C., USA.

Shen, Y.B., X.S. Piao, S.W. Kim, L. Wang and P. Liu et al., 2009. Effects of yeast culture supplementation on growth performance, intestinal health and immune response of nursery pigs. J. Anim. Sci., 87: 2614-2624. DOI: 10.2527/jas.2008-1512

Van Rensburg, C.J., C.E.J. Van Rensburg, J.B.J. Van Ryssen and N.H. Casey et al., 2006. In vitro and in vivo assessment of humic acid as an aflatoxin binder in broiler chickens. Poultry Sci., 85: 1576-1583. PMID: 16977843

Williams, D.E., G. Orner, K.D. Willard, S. Tilton and J.D. Hendricks et al., 2009. Rainbow trout (Oncorhynchus mykiss) and ultra-low dose cancer studies. Comp. Biochem. Physiol. C, 149: 175-181. PMID: 19135172

Yosef, T.A., M.Z. Al-Julaifi, W.M. Salah-El-Dein and A.M. AL-Rizqi, 2013. Assessment of aflatoxin M1 residues in raw cow milk at Al-Riyadh area with reference to some detoxification applications. Life Sci. J., 10: 3365-3369.

Zaghini, A.G., G. Martelli, P. Roncada, M. Simoli and L. Rizzi, 2005. Maman oligosaccharides and aflatoxin B1 and M1 residues in Egs and aflatoxin B1 levels in liver. Poultry Sci., 84: 825-832. PMID: 15971517 